\title{
Transdermal Fentanyl: Pharmacology and Toxicology
}

\author{
Lewis Nelson, $M D^{a}$, Robert Schwaner, $M D^{b}$
}

aDepartment of Emergency Medicine, New York University School of Medicine, New York City Poison Control Center, New York, New York

bDepartment of Emergency Medicine, Our Lady Of Resurrection Medical Center, Chicago, Illinois

\begin{abstract}
Objective: To evaluate the underlying pharmacology, safety, and misuse/abuse of transdermal fentanyl, one of the cornerstone pharmacotherapies for patients with chronic pain.

Methods: Literature was identified through searches of Medline (PubMed) and several textbooks in the areas of pharmacology, toxicology, and pain management. A bibliographical review of articles identified by these searches was also performed. Search terms included combinations of the following: fentanyl, transdermal, patch, pharmacology, kinetics, toxicity, and poisoning. All pertinent clinical trials, retrospective studies, and case reports relevant to fentanyl pharmacology and transdermal fentanyl administered by any route and published in English were identified. Each was reviewed for data regarding the clinical pharmacology, abuse, misuse, and safety of transdermal fentanyl. Data from these studies and information from review articles and pharmaceutical prescribing information were included in this review.

Results: Fentanyl is a high-potency opioid that has many uses in the treatment of both acute and chronic pain. Intentional or unintentional misuse, as well as abuse, may lead to significant clinical consequences, including death. Both the US Food and Drug Administration (FDA) and Health Canada have warned of potential pitfalls associated with transdermal fentanyl, although these have not been completely effective in preventing life-threatening adverse events and fatalities related to its inappropriate use.

Conclusions: Clinically consequential adverse effects may occur unexpectedly with normal use of transdermal fentanyl, or if misused or abused. Misuse and therapeutic error may be largely preventable through better education at all levels for both the prescriber and patient. The prevention of intentional misuse or abuse may require regulatory intervention.
\end{abstract}

\section{INTRODUCTION}

Pain affects all people. Pain may be acute (e.g., injury), episodic (e.g., headaches), or chronic (e.g., sciatic pain); regardless of its nature it decreases a patient's quality of life. The annual societal cost due to lost productivity from pain is conservatively estimated at over 60 billion dollars in the United States [1]. The average worker suffering a disorder associated with pain loses 4 days of work every month compared to a half day for a worker without a pain syndrome. Thus, in addition to improving quality of life, adequate pain control could result in billions of dollars of saved productivity[1].

This article reviews the pharmacology and toxicology of transdermal fentanyl, one of the cornerstone pharmacotherapies for patients with chronic pain. When used as directed and in a safe manner, this long-acting form of a highly-potent medication is ex-

Keywords: fentanyl, transdermal, pharmacology, toxicology, poisoning, opioid

Notes: There was no outside funding of any kind used for this study.

Lewis Nelson has provided support to both plaintiff and defense attorneys about transdermal fentanyl devices. Robert Schwaner has no conflicts of interest to report.

Corresponding Author: Lewis S. Nelson, MD, New York City Poison Control Center, 455 First Avenue, Room 123, New York, NY 10016. Email: lewis.nelson@nyumc.org 
tremely effective in controlling chronic pain. However, there are impediments to the safe use of this formulation. Both the US Food and Drug Administration (FDA) and Health Canada have warned of potential pitfalls associated with transdermal fentanyl $[2,3]$. Despite these initial Public Health Advisories, the FDA continues to receive reports of fentanyl-associated life-threatening adverse events and fatalities related to inappropriate transdermal fentanyl device use [4].

\section{HISTORY AND BACKGROUND}

Fentanyl, a schedule II medication, was introduced in 1960 to replace morphine and other opioids for use in cardiac surgery due to its higher potency (approximately 75- to 100-fold compared to morphine) [5]. It is also associated with fewer adverse cardiovascular effects than morphine and triggers substantially less histamine release. A versatile analgesic, fentanyl is now used frequently for patients with either acute or chronic pain syndromes. Acute and chronic pain are difficult to define specifically, and may coexist. Generally, acute pain begins abruptly, is severe, and is expected to persist for no longer than several days. It usually decreases in intensity during this period. Chronic pain is normally lower in intensity than acute pain, steady in intensity with some variation, and lasts longer than a week-often years.

Delivery of fentanyl for acute pain may occur by intravenous (IV), transmucosal, buccal, epidural, intrathecal, or inhalational routes [6-9]. The pharmacokinetics and clinical effects of fentanyl by these routes in the medical setting are predictable and the drug is considered safe when used by appropriately trained clinicians. However, for practical and pharmacokinetic reasons, fentanyl is indicated for transdermal administration only for the treatment of chronic pain, and generally for use in the outpatient setting. Millions of patients have used a transdermal fentanyl device, also known as the fentanyl patch, to control their chronic pain since approval in 1990 of this medication delivery system by the FDA. Prior to this approval, chronic opioid analgesic therapy was largely limited to oral agents or more invasive means of providing continuous, controlled drug dosing. The transdermal fentanyl device allows opioid analgesia to be provided in a discreet, convenient, noninvasive, and generally safe manner [10-12].

Transdermal delivery of fentanyl was initially studied during the late 1980s in the postoperative setting [13-18], where its safety and efficacy could be evaluated under controlled clinical conditions and with intensive monitoring. Soon thereafter, clinical trials demonstrated that transdermal fentanyl was safe and efficacious for the outpatient treatment of chronic cancer pain [19-24], and subsequently for other pain syndromes. Interestingly, the use of transdermal fentanyl in the postoperative setting is now contraindicated in the prescribing information, though in practice it is occasionally still used by some pain management specialists. The transdermal fentanyl device must be differentiated from patient-controlled iontophoretic transdermal fentanyl delivery systems $[25,26]$.

Adverse events due to transdermal fentanyl device use can be divided into three general categories based largely on intent of use: appropriate therapeutic use, inappropriate therapeutic use (misuse), and abuse. Appropriate therapeutic use is defined as a prescribed use for an appropriate clinical condition in which both the physician and patient use the transdermal device as described by the manufacturer's guidelines. Misuse is defined as misguided use for therapeutic purposes, and may be intentional or unintentional. Misuse may be attributed to either the physician or the patient and includes, for example, prescribed use for an acute pain syndrome by an inadequately informed physician or the intentional application of multiple transdermal devices by a patient for enhanced analgesia [2,4,27-29]. In one report a physician, in an attempt to decrease the dose, improperly advocated that his patient cut the transdermal device into quarters before applying it [30].

Abuse is defined as the intentional inappropriate use of the transdermal device, or its contents, for purposes other than those for which the transdermal device was intended or prescribed. This is typically done with euphoric intent, though it may occasionally be for suicidal reasons.

\section{ADVERSE EVENTS REPORTS OF TRANSDERMAL FENTANYL}

Sales of Johnson \& Johnson's (Janssen) Duragesic transdermal devices have steadily increased since its introduction, and had surpassed 4 million prescriptions and nearly 2 billion dollars in 2004, though sales have fallen with the introduction of generics. Not surprisingly, there has been a concomitant increase in adverse events and emergency department (ED) visits related to the transdermal fentanyl device [31,32]. The reasons for this are unclear and likely multifactorial. In 2004, the Drug Abuse Warning Network (DAWN), a national surveillance database, reported over 8,000 ED visits in the United States due to the misuse of transdermal fentanyl $[31,32]$. This number is likely an underestimate, due to the level of reliability in coding for the various opioids and to the selective and voluntary nature of hospital participation in DAWN.

Although individual case reports confirm the abuse of fentanyl derived from the transdermal delivery system, epidemiological links are less clear. Fentanyl use data is collected by various groups including the Drug Enforcement Administration (DEA), DAWN, and medical examiners $[33,34]$. Although the latter data are fatality related, they often inadequately distinguish between misuse and abuse, and generally fail to specify the form and/or route by which fentanyl was utilized. A more obvious association from the medical examiner literature is the utilization of the transdermal fentanyl delivery systems as a method of suicide $[27,35,36]$. While in many cases the cause of death may be confirmed objectively, deciphering the manner of death to determine who died from fentanyl abuse rather than suicide is often difficult. This decision is largely based on scene investigation, available clinical history and findings, and postmortem determinations, including analytical toxicology testing. However, even determining that fentanyl is the cause of death on the basis of postmortem blood fentanyl concentrations is occasionally fraught 
with difficulty. For example, as discussed later, pharmacodynamic effects, such as opioid tolerance, and pharmacokinetic effects, such as postmortem redistribution, complicate the interpretation of the postmortem blood concentration [27]. See the Relevant Forensic Toxicology section below for further discussion.

\section{CLINICAL PHARMACOLOGY OF TRANSDERMAL FENTANYL PATCHES}

Fentanyl possesses many of the physicochemical properties essential for transdermal use [37]. The molecular weight of fentanyl base is $337 \mathrm{Da}$ [38] within the maximum molecular weight considered suitable for skin permeation (< $1000 \mathrm{Da})$. Fentanyl, unlike morphine and other opioids, is highly potent, and produces desired clinical effects following the systemic absorption of a fraction of a milligram in nontolerant individuals. It is typically considered that drug administration by this route is limited to drugs that are effective at doses of $<2 \mathrm{mg}$ daily [39].

Additionally, fentanyl is sufficiently soluble in both the lipid and aqueous compartments of the skin to allow penetration. In its alkaloid (base) form, fentanyl readily enters the keratinaceous stratum corneum. This layer of the epidermis provides the greatest barrier to the movement of water both into and out of the body [40]. Only substances with sufficient lipid solubility can dissolve and diffuse past the ceramides and other waxy lipids of this dermal layer. Subsequent movement of drug from the lipid layer into the aqueous dermis is required to enable systemic absorption. Thus a chemical must be soluble in both lipid and water to be internalized effectively following dermal application. The relationship between the lipid and water solubility of a chemical is numerically demonstrated by its octanol-water partition coefficient. This is expressed as the concentration ratio of a chemical in octanol and in water while at equilibrium at a given temper- ature. Fentanyl base has an octanol-water partition coefficient of 860 (fentanyl citrate is 717 at $\mathrm{pH}$ 7.4), thus passes through the lipid portion of the epidermis with relative ease. Although fentanyl base and salt (citrate) are similarly bioavailable, the systemic absorption of the base appears to be slightly faster [40]. In comparison, morphine is not very lipophilic and possesses an octanolwater partition coefficient of 0.7 , and predictably demonstrates poor epidermal permeability [37].

The high lipophilicity of fentanyl results in a rapid diffusion into the lipophilic epidermal tissue with subsequent slow movement into the water-rich dermal tissue (Figure 1). This results in the formation of a depot in the keratinaceous layer of the epidermis. This depot formation accounts for the slow onset and prolonged effects of transdermally-delivered fentanyl. Transdermal device application sites are typically rotated in part to prevent serum concentration fluctuations resulting from the development of large depots following consecutive use of the same site.

Other dermal variables affect the rate of transdermal fentanyl absorption. For example, variations in skin thickness and degree of keratinization will alter its systemic bioavailability and account for much of the great interindividual variability observed with transdermal fentanyl absorption [41-43]. This can be seen in Figure 2, in which there is a wide range around the mean serum fentanyl concentration in transdermal fentanyl users. The average skin thickness of the human body is $40 \mu \mathrm{m}$, but ranges between 20 and $80 \mu \mathrm{m}$ based on location, race, age, and gender, among other factors. In skin samples from 8 individuals, there was a $>50 \%$ difference in the permeability of fentanyl [44]. Skin surface areas with similar stratum corneum thickness typically possess similar diffusion rates within an individual, explaining why the chest, extremities, and abdomen are acceptable sites for transdermal device application without the need for any dosage changes $[41,44]$.

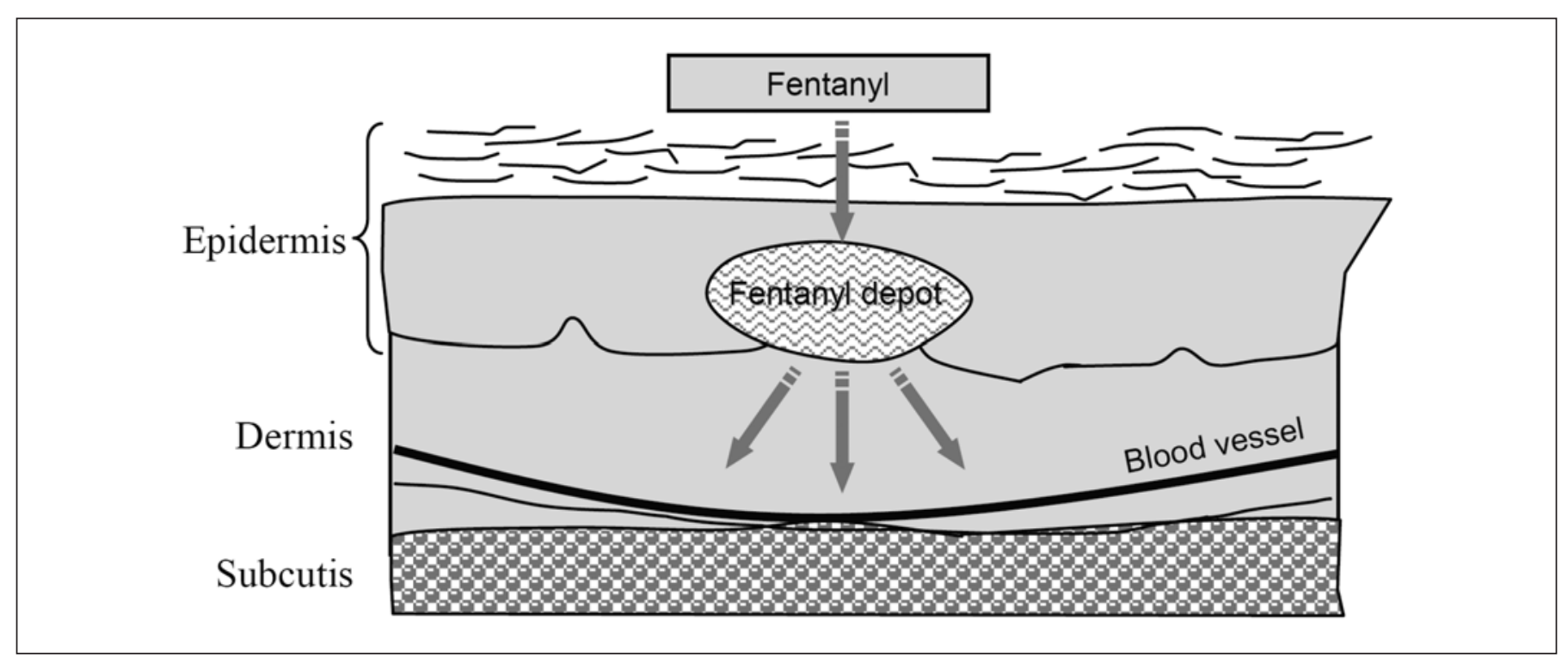

Figure 1: Cross section of skin, demonstrating that fentanyl, given its high lipid solubility, readily enters the epidermal lipids and forms a depot at the dermal-epidermal junction. This slowly dissolves in the hydrophilic dermis and enters the cutaneous blood circulation. 


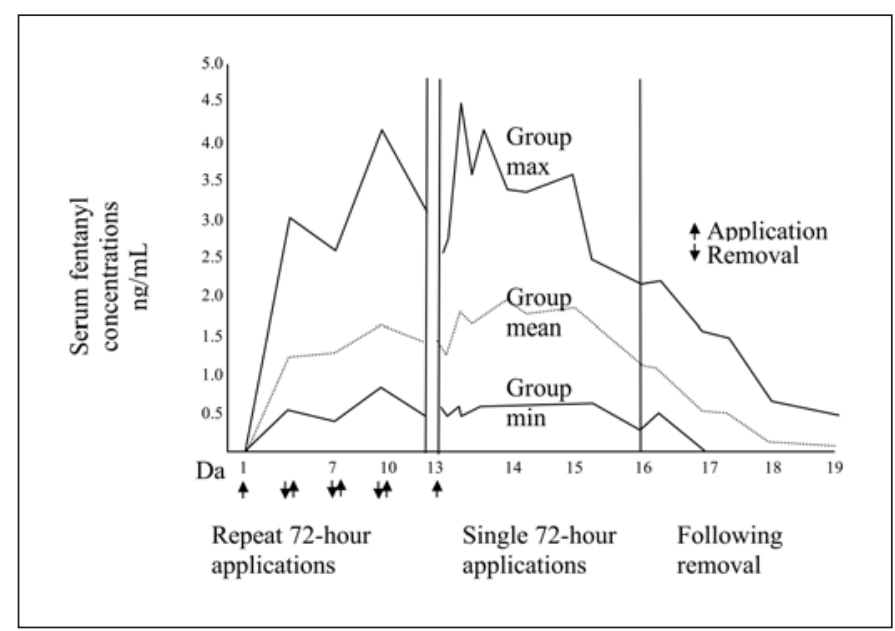

Figure 2: Pharmacokinetics of fentanyl in 10 individuals after application of a $100 \mathrm{~g} / \mathrm{h}$ Duragesic fentanyl transdermal system. Note the wide range of serum fentanyl concentrations both during induction and following attainment of steady state. Derived from Duragsic PI [38].

Following application of a transdermal fentanyl device to broken skin, blood fentanyl concentrations can rise 5-fold [42]. Exposed tissue lacking a stratum corneum, such as mucosa, has a $>30$-fold increase in fentanyl absorption, and more predictable pharmacokinetics [45]. This effect permits the successful use of fentanyl citrate lozenges (Actiq) or buccal tablets (Fentora) for sedation and short-term analgesia, while explaining the potential for morbidity and mortality associated with improper use [46]. Correspondingly, fatal overdose may result from buccal mucosal application of transdermal fentanyl devices [47-51].

Skin temperature elevation enhances the absorption of transdermally-applied fentanyl, perhaps either as a result of cutaneous vasodilation or of enhanced solubility of fentanyl [51-53]. An increase in skin temperature from $32^{\circ} \mathrm{C}$ to $40^{\circ} \mathrm{C}$ leads to a gradual 10- to 15 -fold increase in cutaneous blood flow [54]. A $3^{\circ} \mathrm{C}$ increase in body temperature raises the peak fentanyl blood concentration by $25 \%$ [42]. Case reports detail that elevation in skin or ambient temperatures from external sources such as hot tubs or heating blankets may lead to fentanyl overdose $[4,37,55,56]$. Although blood fentanyl concentrations are often not provided in case reports, a controlled study using a $25 \mu \mathrm{g} /$ hour transdermal fentanyl device showed that the concentration rose rapidly when the transdermal device on the skin was heated to $42^{\circ} \mathrm{C}$ [52]. Application of an overlay to hold in place a nonsticking transdermal device may be associated with altered fentanyl absorption, and raises the potential for toxicity [57]. Further study is essential to determine whether exercise produces dramatic increases in the rate and extent of transdermal absorption, as is demonstrated for the ultrapotent fentanyl analog sufentanil [39].

Intravenously administered fentanyl has a half-life of 2-4 hours but a short duration of action of approximately 15 minutes, due primarily to redistribution [58]. Extensive first-pass he- patic metabolism limits its oral bioavailability [59]. Based on the data provided in the transmucosal fentanyl labeling (Actiq), about $50 \%$ of transmucosal fentanyl is absorbed, with half of this absorbed transmucosally and 25\% escaping first-pass elimination after swallowing [59]. Bypassing the liver explains why the bioavailability of transdermal fentanyl is excellent ( 92\%), which has both advantages and potential liabilities $[45,60,61]$. Once absorbed, fentanyl, like other lipophilic compounds, achieves a large volume of distribution (6 L/kg [range 3-8]) [38].

Fentanyl is a pure mu-opioid receptor agonist that demonstrates approximately 75-100 times the potency of morphine. Its high lipophilicity allows it to readily cross the blood-brain barrier to produce analgesia and sedation. Alterations in blood $\mathrm{pH}$ may affect the distribution of fentanyl between plasma and the central nervous system (CNS) [38].

Metabolism occurs primarily via oxidative dealkylation by hepatic CYP 3A4 to norfentanyl and other less active or inactive metabolites through an oxidative N-dealkylation process. The concomitant use of fentanyl with cytochrome CYP 3A4 inhibitors (e.g., ketoconazole, ritonavir, nefazodone) may result in an increase in both plasma fentanyl concentrations and the risk of adverse drug effects $[2,4]$. A small amount $(8 \%)$ of fentanyl is eliminated unchanged in the urine [38].

\section{TRANSDERMAL DELIVERY SYSTEMS}

There are two general types of transdermal delivery systems currently in clinical use (Figure 3). The original transdermal therapeutic system (TTS), also called the reservoir transdermal device (made by Jannsen [Duragesic] and generics by Sandoz, Watson, Pricara, and Actavis) consists of four functional layers and a protective peel strip [38]. Each of these layers provides important qualities to facilitate consistent and continuous diffusion of fentanyl over a 72-hour period while minimizing the likelihood of

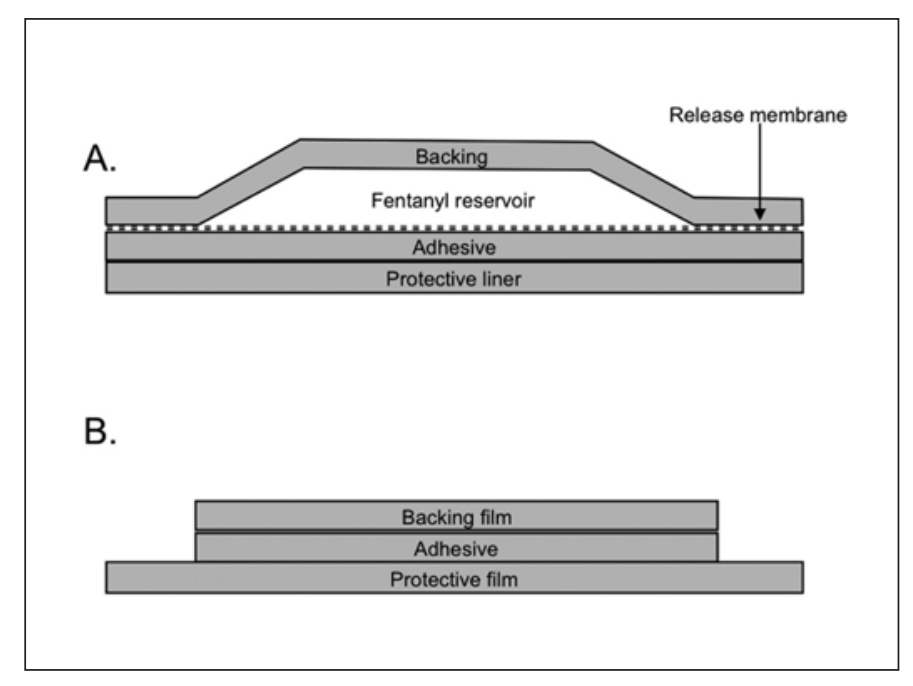

Figure 3: Construction of the reservoir $(A)$ and matrix (B) fentanyl transdermal system. Derived from Duragsic PI [38] and Mylan PI [65]. 
toxicity. The first layer is a polyester film backing that prevents leakage of transdermal device contents onto the surrounding skin. The second layer consists of a drug reservoir, which contains fentanyl and ethanol combined with a hydroxycellulose gel. Ethanol contained within this gel acts as an organic solvent to approximately double the rate of diffusion of fentanyl into the stratum corneum [62]. The quantity of fentanyl contained in this reservoir is appropriate to provide a sufficient concentration gradient for transdermal absorption throughout a 3-day cutaneous application (Table 1).

This reservoir accounts for much of the abuse potential of this transdermal device and for the possibility of dangerous leakage onto nearby skin, both discussed below.

The third layer, an ethylene vinyl acetate copolymer rate-controlling membrane, regulates the rate of delivery of fentanylethanol mixture to the skin surface. This reduces the variations in dermal transport and effectively slows diffusion and subsequent absorption by about 50\%, an effect most important for those in the population who possess faster-than-average transdermal absorption $[38,42,44,45]$. It allows $2.5 \mu \mathrm{g}$ of fentanyl to diffuse across each square centimeter of transdermal device per hour. Thus, a $100 \mu \mathrm{g} / \mathrm{hour}$ transdermal device is constructed to have a skin surface area exposure of $40 \mathrm{~cm}^{2}$ (see Table 1) [63].

The silicone skin adhesive represents the last layer of the transdermal fentanyl device, providing a nonirritating and secure surface area of skin contact. By containing fentanyl itself, the adhesive facilitates the development and maintenance of therapeutic fentanyl concentrations following initial transdermal device application and each subsequent change, respectively. The diffusion that occurs from this silicone adhesive layer also demonstrates that transdermal fentanyl absorption occurs in the absence of an ethanol copolymer $[39,45]$.

More recently introduced to the market, the fentanyl transdermal system (FTS; the generic device by Mylan), commonly called the matrix patch, consists of two functional layers and a protective peel strip. The two functional layers are a backing layer of polyolefin film and a fentanyl-containing silicone adhesive layer. The major difference from the TTS is the absence of a fluid fentanyl reservoir and therefore the ethanol coadsorbant. The pharmacokinetics and clinical effects of the matrix transdermal device are purportedly similar to that of the original transdermal device despite the absence of a reservoir and a rate-controlling membrane [64]. This suggests that skin contact is a consequential variable in determining the absorption pharmacokinetics of fentanyl. Interestingly, the FDA did not require additional pharmacological data prior to approving the generic matrix transdermal device despite this distinct design difference. The prescribing information is essentially identical for the two transdermal devices [65]. This approach raised debate among the various producers of transdermal fentanyl products regarding the appropriateness of accepting the prescribing information for the initial transdermal fentanyl delivery system as representative of the generic product despite a distinct release mechanism [66-68].

Application of fentanyl to the skin in an alternative transdermal device (transdermal fentanyl delivery system [FTDS]) that does not have the same rate-limiting membrane as the reservoir transdermal device results in more rapid and more variable absorption as well as a higher complication rate [69]. This highlights the role for the rate limiting membrane in the transdermal device in controlling the functional bioavailability of fentanyl. This experimental transdermal device, containing about $9 \mathrm{mg}$ of fentanyl, resulted in a 20-fold range in plateau plasma concentrations (0.34-6.75 $\mathrm{ng} / \mathrm{mL}) ; 3$ of 14 patients were withdrawn from the study due to consequential opioid poisoning [69]. Another transdermal delivery system consisting of fentanyl dissolved in dipropylene glycol within a silicone matrix has similar pharmacokinetic qualities as the reservoir transdermal device [70].

\section{PHARMACOKINETICS OF THE TRANSDERMAL FENTANYL DEVICE}

Fentanyl becomes detectable in the serum within 1-2 hours of application of a transdermal fentanyl device. However, therapeutic serum fentanyl concentrations are not achieved until approximately 12-16 hours after transdermal device application $[16,61,71,72]$. The mean time to maximal serum concentrations

Table 1: Physical and Pharmacokinetic Characteristics of the Transdermal Fentanyl Device

\begin{tabular}{lcccc}
\hline $\begin{array}{l}\text { Transdermal } \\
\text { Device } \\
\text { Strength }\end{array}$ & $\begin{array}{c}\text { Transdermal } \\
\text { Device } \\
\text { Surface } \\
\left.\text { Area (cm } \mathbf{( c m}^{2}\right)\end{array}$ & $\begin{array}{c}\text { Fentanyl } \\
\text { Content }(\mathbf{m g})\end{array}$ & $\begin{array}{c}\text { Mean (SD) } \\
\text { Time to } \\
\text { Maximal } \\
\text { Concentration (h) }\end{array}$ & $\begin{array}{c}\text { Mean (SD) } \\
\text { Maximal Plasma } \\
\text { Concentration } \\
\text { (ng/mL) }\end{array}$ \\
\hline $12.5 \mu \mathrm{g} / \mathrm{h}$ & 5 & 1.25 & $27.5(9.6)$ & $0.3(0.2)$ \\
\hline $25 \mu \mathrm{g} / \mathrm{h}$ & 10 & 2.5 & $38.1(18.0)$ & $0.6(0.3)$ \\
\hline $50 \mu \mathrm{g} / \mathrm{h}$ & 20 & 5 & $34.8(15.4)$ & $1.4(0.5)$ \\
\hline $75 \mu \mathrm{g} / \mathrm{h}$ & 30 & 7.5 & $33.5(14.5)$ & $1.7(0.7)$ \\
\hline $100 \mu \mathrm{g} / \mathrm{h}$ & 40 & 10 & $36.8(15.7)$ & $2.5(1.2)$ \\
\hline Data derived from reference 38 & & & \\
\hline
\end{tabular}


(Cmax) averages about 36 hours, regardless of the transdermal device strength, but there is substantial intersubject variability (17-48 hours) $[16,73]$. The Cmax achieved, which depends on the "strength" of the transdermal device, ranges from $0.3 \mathrm{ng} / \mathrm{mL}$ for a $12.5 \mu \mathrm{g} /$ hour transdermal device to $2.6 \mathrm{ng} / \mathrm{mL}$ for a $100 \mu \mathrm{g} /$ hour transdermal device [16,73]. For reference, an IV bolus of $2 \mathrm{~g} / \mathrm{kg}$ produces a peak serum concentration of $11 \mathrm{ng} / \mathrm{mL}$ [74]. In comparison, an effective postoperative analgesic serum concentration is $0.3-0.7 \mathrm{ng} / \mathrm{mL}$ [15]. These concentrations are substantially higher than those tolerated by an opioid-naïve patient, demonstrating the development of opioid tolerance with continued use. The apparent half-life of fentanyl delivered by a transdermal device (following its removal) approaches 17 hours (16-22 hours) due to continued absorption from the stratum corneum depot during the elimination phase $[16,58,61,72,73]$. Based on clinical studies and those with human epidermal cells, dermal metabolism is considered inconsequential $[61,75,76]$.

One of the advantages of this form of fentanyl delivery is exemplified by the relatively smooth pharmacokinetic curve of blood fentanyl concentrations that is produced by transdermal device delivery, particularly when compared to intermittent dosing by virtually any other route. Figure 2 demonstrates that the mean curve of serum fentanyl concentration is relatively flat over the 3-day period following reaching steady state, without the peaks and troughs typical of intermittent dosing. There is a somewhat wide range between the minimum and maximum serum concentrations attained, highlighting the importance of close observation during the initiation of this therapy. Elderly patients have a slightly longer time to peak concentration and a prolonged half-life following removal of the transdermal device [77]. In 1.5- to 5-year-old patients, the fentanyl plasma concentrations were approximately twice as high as that of adult patients [38]. In older pediatric patients, the pharmacokinetic parameters were similar to that of adults. A review of the use of the reservoir transdermal device in children undergoing treatment for cancerrelated pain suggests that individual pharmacokinetics parameters of transdermal fentanyl seem to differ from adults (e.g., longer time to reach steady-state serum concentrations, higher weightbased clearance), safety concerns remain, and there is a significant need for additional information [78]. The effects of cachexia, muscle wasting, or other debilitating diseases on fentanyl pharmacokinetics are not well studied.

\section{CLINICAL EFFECTS}

The clinical effects of fentanyl, regardless of route of administration, are similar to those of other opioids, and are similarly dependent on both the dose and the degree of patient tolerance. At serum fentanyl concentrations of $0.63-1.5 \mathrm{ng} / \mathrm{mL}$, postoperative analgesia is produced in most opioid-naïve patients [15]. Hypoventilation begins to manifest at concentrations $>1.5 \mathrm{ng} / \mathrm{mL}$, a subtherapeutic serum concentration for some [79-81].

With escalating doses, analgesia is preserved and mild sedation is noted. Patients in this state are easily arousable with phys- ical stimulation. As concentrations increase further, deep sedation develops, requiring greater stimulation, and the arousal period shortens. Further increasing fentanyl concentrations produces coma, with the inability to arouse the patient. Respiratory depression essentially parallels sedation and analgesia, with the eventual development of apnea. Simultaneous loss of protective airway reflexes highlights the requirement for advanced ventilatory management skills. Serum fentanyl concentrations of $3.0 \mathrm{ng} / \mathrm{mL}$ typically produce these latter effects in opioid-naïve patients.

Miosis is a common side effect and may be used diagnostically to identify both compliance and overdose. Gastrointestinal effects, dyspnea, and pruritis can be discomforting [82]. The rigid chest syndrome associated with fentanyl infusion is not well described with the transdermal fentanyl device. This may be related to the slower rate of rise of the serum levels with transdermal fentanyl devices than with IV infusion [83]. Mydriasis, vomiting and diarrhea, and piloerection may be used to identify opioid withdrawal.

\section{THERAPEUTIC CONSIDERATIONS}

The maintenance of a relatively steady serum concentration with transdermal fentanyl, which is particularly difficult for drugs with short half-lives, results in reduced side effects and improved efficacy. This improves therapeutic compliance, which is perhaps less of an issue with analgesics than with other transdermally-administered drugs (e.g., estrogen, clonidine). However, in patients with chronic pain, the substitution of transdermal fentanyl for other opioids is often considered as much for convenience (e.g., reduced dosing frequency, covert use) as for any specific analgesic benefit. This highlights the importance of weighing the overall therapeutic benefit of a drug and its delivery system against its overall safety aspects in the associated risk-benefit analysis.

Several approaches have been developed for initiating transdermal fentanyl therapy, but central to all is the presupposition of preexistent opioid tolerance [38]. The transdermal fentanyl device should only prescribed for patients who are already receiving long-term therapy with strong oral or parenteral opioids (strong opioids include morphine and oxycodone, not codeine). Tolerance in this situation is difficult to define quantitatively, but it is often suggested that the patient should be on at least the equivalent of morphine $60 \mathrm{mg}$ daily for more than a week (this can be, for example, at least $30 \mathrm{mg}$ of oral oxycodone daily, or at least $8 \mathrm{mg}$ of oral hydromorphone daily for this period of time) [38]. Due to the interindividual pharmacokinetic differences as well as the dose-response (pharmacodynamic) variability, the process of initiating transdermal fentanyl therapy is often associated with unpredictable clinical responses. As in the use of methadone, a long-acting oral opioid, the initiation of therapy prior to the development of steady-state pharmacokinetics may be the period of greatest risk. Determination of an appropriate starting dose of the transdermal fentanyl device can be complex, and incorrect selection of the dose may result in over- or underdosing. Because of this concern, patients may be initiated on transdermal therapy in the hospital. Conversion tables exist for 
calculating an expected transdermal fentanyl device dose requirement for patients on prior chronic oral opioid therapy [38]. Dose finding is often necessary, and short-acting opioid adjunctswhether oral or IV-will often be necessary to control pain until therapeutic serum fentanyl concentrations are achieved, and often afterwards.

Several recent literature reports suggest that certain patients who are not tolerant to strong opioids, and even opioid-naïve patients, may safely receive a low-dose transdermal fentanyl device $[84,85]$. The approach of slowly escalating from a 12.5 or 25 $\mu \mathrm{g} /$ hour transdermal device should provide a degree of safety from opioid overdose. This approach requires specialized knowledge and a highly-selected patient population, and is inconsistent with most current guidelines for the initiation of a transdermal fentanyl device. In addition, physician knowledge of appropriate transdermal fentanyl use is generally poor, and recent reports raise concerns about the use of these delivery systems without an adequate understanding of their pharmacology and toxicology $[71,86]$.

Patients with acute pain syndromes are not appropriate candidates for transdermal fentanyl [38]. This group risks developing opioid toxicity as their acute painful stimulus, and its associated analgesic requirements, resolves. This time-limited pain syndrome is incompatible with the predicted pharmacokinetics of the transdermal fentanyl device (see above). The package insert for the transdermal fentanyl device [38] and several FDA advisories [2,4] specifically note the contraindication of transdermal fentanyl to control postoperative pain. However, some pain specialists advocate transdermal fentanyl for postoperative pain using extreme caution and close clinical monitoring.

Considering the time involved to attain a new steady-state serum fentanyl concentration after dose escalation (approximately 3-5 days) stacking of sequential doses with resultant fentanyl toxicity may occur. This delay to steady-state kinetics illustrates the importance of the utilization of short-acting opioids during both the initiation and transitioning of transdermal fentanyl device doses [38].

Even among opioid-tolerant patients, starting any strength transdermal device outside of the hospital or with a transdermal device that delivers greater than $25 \mu \mathrm{g} /$ hour should be done with great caution and is discouraged [38]. Subsequent dosing increases would also ideally occur in small increments (perhaps in the hospital), only after the previous transdermal device had been applied for 3 days.

\section{INTENTIONAL TRANSDERMAL FENTANYL DEVICE MISUSE AND ABUSE}

Fentanyl is reportedly commonly abused by healthcare professionals [87] and its analogues have been implicated in several large epidemics of "heroin" poisoning [88]. Fentanyl abusers note that it produces euphoric effects that are similar to heroin [89]. Transdermal fentanyl devices are suitable for abuse in several ways. The fluid state of the drug reservoir layer allows fentanyl to be extracted. Every transdermal device, even after being used, contains a significant quantity of fentanyl. Even the smallestdose transdermal device contains $1.25 \mathrm{mg}$ (or $1250 \mu \mathrm{g}$ ) of fentanyl (see Table 1). This is 10-20 times the typical initial IV therapeutic dose of $50-100 \mu \mathrm{g}[1 \mu \mathrm{g} / \mathrm{kg}]$ used during procedural analgesia and sedation. Many of the fatalities reported from abuse of the transdermal fentanyl device are associated with IV administration of the fentanyl-containing gel extracted from the reservoir transdermal device [35,90-94]. One interesting report based on information from a street user suggests that the matrix transdermal device is preferred over the reservoir transdermal device by Canadian opioid abusers [95]. By cutting the matrix transdermal device into the desired size, users can place the fragment in their mouth, allowing rapid transmucosal absorption [67]. Fentanyl may also be eluted from the transdermal device using solvents and then injected [67]. Similar reports can be found on the Internet (e.g., http://www.bluelight.ru).

Other reported routes of abuse include inhalation of a pyrolyzed transdermal device, insertion of a transdermal device rectally, and drinking water in which a transdermal fentanyl device was steeped as a tea bag [96-98]. Despite its poor oral bioavailability, ingestion of fentanyl gel may result in poisoning and death $[35,48,50,99,100]$. It remains unclear to what extent transdermal device ingestion-related fatalities are due to sublingual, transmucosal, or gastrointestinal absorption, or a combination thereof. Fentanyl in other formulations intended for transmucosal absorption (e.g., Fentora, Actiq) has resulted in fentanyl morbidity and mortality $[59,101]$. Even accounting for fentanyl's poor enteral bioavailability, each transdermal device contains a sufficient amount of fentanyl to be lethal.

Previously-worn transdermal devices may contain $28-84 \%$ of the initial drug [102]. Transdermal fentanyl devices have been reportedly removed from decedents and nursing home patients for subsequent abuse [103], prompting healthcare facilities to develop policies for their safe disposal. Exposure to discarded or misplaced transdermal devices has also proven consequential [100]. The manufacturers and FDA have gone to substantial lengths to educate patients (e.g., fold the sticky side together and flush down a toilet) and provide safe mechanisms for transdermal device use and disposal, largely to prevent unintentional childhood exposure to discarded transdermal devices $[4,100,104,105]$.

\section{TRANSDERMAL DEVICE LEAK}

Concerns for dysfunction of the TTS polyester backing with subsequent fentanyl poisoning following gel leakage onto intact skin prompted the manufacturers to issue an "urgent product recall" in 2004 of more than 2 million transdermal devices [106,107]. They noted the possibility that "a small percentage of these transdermal devices which were distributed in the U.S. may leak medication along one edge" due to a "fold over defect" of the backing material, which occurred during the manufacturing process. The company estimated that $<19,000$ transdermal devices out of a lot total of 440,000 ( 5\%) were potentially defective. Reservoir leak- 
age during clinical use could cause the fentanyl-containing gel to spread over the skin, increasing the surface area for absorption and also accelerating the evaporation of the alcohol and water solvents of the gel. Currently undefined, this evaporative process may speed or slow the delivery of fentanyl across the epidermis. Although improved manufacturing practices and strict quality assurance procedures were implemented by the manufacturers, two additional recalls due to potential membrane defects were issued in early 2008 [108,109].

\section{RELEVANT FORENSIC TOXICOLOGY}

The most consistent pathological finding on postmortem examination is pulmonary edema [110], and as with other opioid fatalities, such as heroin or methadone, the nonspecific pathology findings require that the determination of the cause of death await the toxicological analysis. In many of the transdermal fentanyl fatality reports the clinical exposures are inadequately detailed (or not readily discernable), which may increase the complexity of the cause of death determination. Additionally, many of these reports involve concomitant exposures to other substances in often undefined concentrations, hampering the ability to fully appreciate the role of fentanyl. Because of the lack of structural similarity, fentanyl should not be expected to produce a positive result on the opioid/opiate component of a standard immunoassay-based "urine drug screen" [111]. Liquid chromatography-mass spectrometry is the established standard for measuring serum fentanyl concentrations [112].

In a large series of fatalities from fentanyl abuse (not transdermal device-related), the mean postmortem blood concentration was $3 \mathrm{ng} / \mathrm{mL}$ [110]. Another similar series reported a range in serum concentration of $5-120 \mathrm{ng} / \mathrm{mL}$, with a median of 22 $\mathrm{ng} / \mathrm{mL}$, in 19 fatalities deemed to be due to drug overdose, though not necessarily abuse related [113]. Several of the deaths were associated with transdermal fentanyl delivery systems; one patient on a transdermal fentanyl dose of $300 \mu \mathrm{g} / \mathrm{hour}$ had a postmortem blood fentanyl concentration of $120 \mathrm{ng} / \mathrm{mL}$.

The mean measured fentanyl blood concentration in 6 transdermal fentanyl fatalities was $21 \mathrm{ng} / \mathrm{mL}(10-38 \mathrm{ng} / \mathrm{mL})$ [35] In a series of 25 deaths potentially involving transdermal fentanyl, the 8 cases felt to be "clearly not related" had heart blood concentrations of $<2-7 \mathrm{ng} / \mathrm{mL}$, while in the 12 cases considered attributable solely to fentanyl the heart blood concentrations ranged from 16 to $139 \mathrm{ng} / \mathrm{mL}$ [27]. Postmortem redistribution is considered to be minor, though variable, with a heart/femoral ratio of 1.6 (range $0.7-4.6$ ) noted in a study of 13 transdermal fentanyl device-related fatalities [27].

In one reported case, in which an elderly woman applied 10 transdermal fentanyl devices simultaneously in a successful suicide attempt, the femoral blood concentration was $21.3 \mathrm{ng} / \mathrm{mL}$ in right femoral blood, $37.6 \mathrm{ng} / \mathrm{mL}$ in right ventricular blood, and $33.9 \mathrm{ng} / \mathrm{mL}$ in left ventricular blood. Corresponding norfentanyl concentrations were $<2 \mathrm{ng} / \mathrm{mL}, 4.2 \mathrm{ng} / \mathrm{mL}$, and $4.4 \mathrm{ng} / \mathrm{mL}$, respectively [29]. An 83-year-old woman who had three $100 \mu \mathrm{g} /$ hour transdermal devices on her skin had a blood fentanyl concentration of $25 \mathrm{ng} / \mathrm{mL}$ [36]. Injection administration from a transdermal fentanyl device resulted in blood fentanyl concentrations of $2.7 \mathrm{ng} / \mathrm{mL}$ and $13.8 \mathrm{ng} / \mathrm{mL}$ in 2 decedents who extracted the drug from a $100 \mu \mathrm{g} /$ hour transdermal device [94].

Although it would not be surprising that transdermal fentanyl device injection abuse would result in higher blood concentrations than with transdermal use, in one study of 23 transdermal fentanyl device-related deaths, the fatalities associated with a transdermal route of poisoning had higher mean blood fentanyl concentrations (21 $\mathrm{ng} / \mathrm{mL})$ than those with an IV route $(7 \mathrm{ng} / \mathrm{mL})$ [35].

In a series of 25 deaths potentially involving transdermal fentanyl, those "clearly not related" had liver concentrations of 5.8-31 ng/g while those deemed fentanyl related had concentrations of $69-352 \mathrm{ng} / \mathrm{g} .{ }^{27}$

Following oral ingestion of a used $25 \mu \mathrm{g} /$ hour transdermal fentanyl delivery system, a 1-year-old girl had the following fentanyl and norfentanyl concentrations: peripheral blood, 5.6 and $5.9 \mathrm{ng} / \mathrm{mL}$; heart blood, 19.0 and $8.9 \mathrm{ng} / \mathrm{mL}$; and liver, 235 and $26 \mathrm{ng} / \mathrm{g}$ [100]. This suggests that although first-pass hepatic metabolism is substantial, poisoning following transdermal device ingestion remains a concern.

\section{MANAGEMENT OF FENTANYL POISONING}

The management of fentanyl poisoning, whether transdermal or another route, should focus on ventilatory support and oxygenation first and foremost. This is most typically provided by bagvalve-mask ventilation, although endotracheal intubation or other measures (e.g., laryngeal mask airway) may be needed in some patients. Although naloxone effectively antagonizes fentanyl at the mu-opioid receptor and may avoid intubation in many, it may be avoided best in mildly-poisoned, nonvomiting, opioid-tolerant patients with adequate spontaneous ventilation. Patients provided solely supportive care will not awaken immediately, which may not prove satisfactory to the clinical staff. However, administration of naloxone in conventional (0.4-2 mg) dose to this latter group of patients is associated with fulminant awakening and precipitated opioid withdrawal, with its attendant complications [114]. In addition, recrudescence of an underlying pain syndrome, if present, may be undesirable. Judicious titration, starting at very low doses (e.g., $0.05 \mathrm{mg}$ IV), while providing ventilatory support and oxygenation, may provide a more gradual, and safer, awakening. Failure to arouse with an appropriately-titrated dose of naloxone may signal the presence of an overlooked diagnosis, such as a concomitant exposure or cerebral hypoxia. Due to the high potency of fentanyl, higher-than-conventional doses of naloxone may be required on rare occasions.

Although the transdermal fentanyl device should be immediately removed, this is inadequate monotherapy as the reservoir of fentanyl in the stratum corneum will continue to deliver fentanyl systemically for several hours [38]. Although the skin should be cleansed to remove any external drug, the rapidity of absorption makes the benefit of this questionable. Additionally, cleansing 
would likely have limited or no effect on removing intradermal fentanyl. The optimal cleansing compound is undefined, and soap and water are likely acceptable. It would be appropriate to completely examine the patient for the presence of an unsuspected transdermal fentanyl device.

\section{CONCLUSION}

Fentanyl is an extremely potent opioid carrying significant analgesic benefit, but capable of causing considerable harm. Furthermore, transdermal administration of fentanyl extends many of the drug's therapeutic benefits, but also adds unique factors that may complicate the drug's safety. There are many reasons for the enhanced toxicity, including inappropriate prescription and improper use. As a potent opioid analgesic in a concentrated transdermal device system, its abuse potential is extremely high and carries a high risk of morbidity or mortality. Physician education and awareness concerning the numerous and often resourceful ways with which transdermal fentanyl may be misused or abused hopefully will result in fewer poor outcomes and ultimately save lives.

\section{REFERENCES}

1. Stewart WF, Ricci JA, Chee E, et al. Lost productive time and cost due to common pain conditions in the US workforce. JAMA. 2003;290:2443-2454.

2. Food and Drug Administration [webpage on the Internet]. Public Health Advisory: Safety warnings regarding use of fentanyl transdermal skin patches [updated 15 July 2005; cited 1 March 2008]. Available from: http://www.fda.gov/cder/drug/advisory/ fentanyl.htm

3. Health Canada [webpage on the Internet]. Important Safety Information: Duragesic ${ }^{\circledR}$ fentanyl transdermal system [updated 13 September 2005; cited 1 March 2008]. Health Canada. Available from: http://www.hc-sc.gc.ca/dhp-mps/ medeff/advisories-avis/prof/2005/duragesic_hpc-cps_e.html

4. Food and Drug Administration [webpage on the Internet]. Information for Healthcare Professionals: Fentanyl Transdermal System (marketed as Duragesic and generics) [updated 21 December 2007; cited 24 Feb 2008]. Available from: http://www. fda.gov/cder/drug/InfoSheets/HCP/fentanyl_2007HCP.htm

5. Stanley TH. The history and development of the fentanyl series. J Pain Symptom Manage. 1992;7:S3-S7.

6. Foley KM. Preface. J Pain Symptom Manage. 1992;7:S1-S2.

7. Payne R. Transdermal fentanyl: Suggested recommendations for clinical use. J Pain Symptom Manage. 1992;7:S40-S44.

8. Patt RB, Hogan LA. Transdermal fentanyl for chronic cancer pain: detailed case reports and the influence of confounding factors. J Pain Symptom Manage. 1992;7:S51-S53.

9. Newshan G, Lefkowitz M. Transdermal fentanyl for chronic pain in AIDS: A pilot study. J Pain Symptom Manage. 2001;21:69-77.
10. Slover R. Transdermal Fentanyl: Clinical Trial at the University of Colorado Health Sciences Center. J Pain Symptom Manage. 1992;7:S45-S47.

11. Simmonds MA, Richenbacher J. Transdermal fentanyl: long-term analgesic studies. J Pain Symptom Manage. 1992;7: S36-39.

12. Herbst LH, Strause LG. Transdermal fentanyl use in hospice home-care patients with chronic cancer pain. J Pain Symptom Manage. 1992;7:S54-S57.

13. van Lersberghe C, Camu F, de Keersmaecker E, et al. Continuous administration of fentanyl for postoperative pain: a comparison of the epidural, intravenous, and transdermal routes. J Clin Anesth. 1994;6:308-314.

14. van Bastelaere M, Rolly G, Abdullah NM. Postoperative analgesia and plasma levels after transdermal fentanyl for orthopedic surgery: double-blind comparison with placebo. J Clin Anesth. 1995;7:26-30.

15. Gourlay GK, Kowalski SR, Plummer JL, et al. Fentanyl blood concentration-analgesic response relationship in the treatment of postoperative pain. Anesth Analg. 1988;67:329-37.

16. Gourlay GK, Kowalski SR, Plummer JL, et al. The transdermal administration of fentanyl in the treatment of postoperative pain: pharmacokinetics and pharmacodynamic effects. Pain. 1989;37:193-202.

17. Sandler AN, Baxter AD, Katz J, et al. A double-blind, placebo-controlled trial of transdermal fentanyl after abdominal hysterectomy: analgesic, respiratory, and pharmacokinetic effects. Anesthesiology. 1994;81:1169-1180.

18. Miguel R, Kreitzer JM, Reinhart D, et al. Postoperative pain control with a new transdermal fentanyl delivery system: a multicenter trial. Anesthesiology. 1995;83:470-477.

19. Hammack JE, Mailliard JA, Loprinzi CL, et al. Transdermal fentanyl in the management of cancer pain in ambulatory patients: an open-label pilot study. J Pain Symptom Manage. 1996;12:234-240.

20. Grond S, Zech D, Lehmann, KA, et al. Transdermal fentanyl in the long-term treatment of cancer pain: a prospective study of 50 patients with advanced cancer of the gastrointestinal tract or the head and neck region. Pain. 1997;69: 191-198.

21. Ahmedzai S. New approaches to pain control in patients with cancer. Eur J Cancer. 1997;6:S8-S14.

22. Donner B, Zenz M, Strumpf M, et al. Long-term treatment of cancer pain with transdermal fentanyl. J Pain. Symptom Manage. 1998;15:168-175.

23. Sloan PA, Moulin DE, Hays H. A clinical evaluation of transdermal therapeutic system fentanyl for the treatment of cancer pain. J Pain Symptom Manage. 1998;16:102-111.

24. Gourlay GK. Treatment of cancer pain with transdermal fentanyl. Lancet. 2001;2:165-172.

25. Viscusi ER, Reynolds L, Chung F, et al. Patient-controlled transdermal fentanyl hydrochloride vs intravenous morphine pump for postoperative pain: a randomized controlled trial. JAMA. 2004;291:1333-1341. 
26. Viscusi ER, Siccardi M, Damaraju CV, et al. The safety and efficacy of fentanyl iontophoretic transdermal system compared with morphine intravenous patient-controlled analgesia for postoperative pain management: an analysis of pooled data from three randomized, active-controlled clinical studies. Anesth Analg. 2007;105:1428-1436.

27. Anderson DT, Muto JJ. Duragesic ${ }^{\circledR}$ transdermal patch: postmortem tissue distribution of fentanyl in 25 cases. J Anal Toxicol. 2000;24:627-634.

28. Low JA, Chye R. A pitfall to avoid when starting a patient on transdermal fentanyl. Aust Fam Physician. 2000;29: 1173-1175.

29. Coopman V, Cordonnier J, Pien K, et al. LC-MS/MS analysis of fentanyl and norfentanyl in a fatality due to application of multiple Durogesic transdermal therapeutic systems. Forensic Sci Int. 2007;169:223-227.

30. Klockegether-Radke A, Hildebrandt J. Opioid intoxication: inappropriate administration of transdermal fentanyl. Anaesthesist. 1997;46:428-429.

31. National Institute of Drug Abuse, Community Epidemiology Working Group [webpage on the Internet]. Epidemiologic trends in drug abuse. Advanced report: Prescription drug abuse [updated June 2004; cited 1 March 2008]. NIH Publication No. 04-5363A. Available from:

http://www.drugabuse.gov/PDF/CEWG/AdvReport604.pdf

32. Substance Abuse and Mental Health Services Administration, Office of Applied Studies. Drug Abuse Warning Network, 2004: National Estimates of Drug-Related Emergency Department Visits. Rockville, MD: Substance Abuse and Mental Health Services Administration; 2006. DAWN Series D-28, DHHS Publication No. (SMA) 06-4143.

33. Henderson GL. Designer drugs: past history and future prospects. J Forensic Sci. 1998;33:569-575.

34. Jerrard DA. "Designer drugs" - a current perspective. J Emerg Med. 1990;8:733-741.

35. Kuhlman JJ, McCaulley R, Valouch TJ, et al. Fentanyl use, misuse, and abuse: a summary of 23 postmortem cases. J Anal Toxicol. 2003;27:499-504.

36. Edinboro LE, Poklis A, Trautman D, et al. Fatal fentanyl intoxication following excessive transdermal application. J Forensic Sci. 1997;42:741-743.

37. Lehmann KA, Zech D. Transdermal fentanyl: clinical pharmacology. J Pain Symptom Manage. 1992;7:S8-S16.

38. Janssen Pharmaceutical [webpage on the Internet]. Duragesic ${ }^{\circledast}$ approved package insert. Titusville, NJ. [updated April 2007; cited 1 March 1, 2008]. Available from: http://www. duragesic.com/duragesic/shared/pi/duragesic.pdf

39. Sebel PS, Barrett CW, Kirk CJ, et al. Transdermal absorption of fentanyl and sufentanil in man. Eur J Clin Pharmacol. 1987;32:529-531.

40. Sandler A. Transdermal fentanyl: acute analgesic clinical studies. J Pain Symptom Manage. 1992;7:S27-S35.

41. Solassol I, Bressolle F, Caumette L, et al. Inter- and intraindividual variabilities in pharmacokinetics of fentanyl after repeated 72-hour transdermal applications in cancer pain patients. Ther Drug Monit. 2005;27:491-498.

42. Gupta SK, Southam M, Gale R, et al. System functionality and physiochemical model of fentanyl transdermal system. J Pain Symptom Manage. 1992;7:S17-S26.

43. Karst M, Fink M, Wagner T, et al. Transdermal fentanyl: little absorption in two patients with systemic sclerosis? Pain Medicine. 2001;2:225-227.

44. Larsen RH, Nielsen F, Sørensen JA, et al. Dermal penetration of fentanyl: inter- and intraindividual variations. Pharmacol Toxicol. 2003;93:244-248.

45. Roy SD, Flynn GL. Transdermal delivery of narcotic analgesics: $\mathrm{pH}$, anatomical and subject influences on cutaneous permeability of fentanyl and sufentanil. Pharm Res. 1990;7:842-847.

46. Cephalon, Inc. [webpage on the Internet]. Fentora prescribing information. Frazer, PA [updated October 2007; cited 1 March 2008]. Available from: http://www.fentora.com/ HCP/pi.pdf

47. Kramer C, Tawney M. A fatal overdose of transdermally administered fentanyl. J Am Osteopath Assoc. 1998;98:385-386.

48. Arvanitis ML, Satonik RC. Transdermal fentanyl abuse and misuse. Am J Emerg Med. 2002;20:58-59.

49. Liappas IA, Dimopoulos NP, Mellos E et al. Oral transmucosal abuse of transdermal fentanyl. J Psychopharmacol.

2004;18:277-280.

50. Roberge RJ, Krenzelok EP, Mrvos R. Transdermal drug delivery system exposure outcomes. J Emerg Med. 2000;18:147-151.

51. Newshan G. Heat-related toxicity with the fentanyl transdermal patch. J Pain Symptom Manage. 1998;16:277-278.

52. Ashburn MA, Ogden LL, Zhang J, et al. The pharmacokinetics of transdermal fentanyl delivered with and without controlled heat. J Pain. 2003;4:291-297.

53. Shomaker TS, Zhang J, Ashburn MA. Assessing the impact of heat on the systemic delivery of fentanyl through the transdermal fentanyl delivery system. Pain Med. 2000;1: 225-230.

54. Song CW, Chelstrom LM, Levitt SH, et al. Effects of temperature on blood circulation with laser Doppler method. Int J Radiat Oncol Biol Phys. 1989;17:1041-1047.

55. Rose PG, Macfee MS, Boswell MV. Fentanyl transdermal system overdose secondary to cutaneous hyperthermia. Anesth Analg. 1993;77:390-391.

56. Frolich M, Giannotti A, Modell JH. Opioid overdose in a patient using a fentanyl patch during treatment with a warming blanket. Anesth Analg. 2001;93:647-648.

57. Mylan Laboratories, Inc. [webpage on the Internet]. Citizens petition (2006P-0123) FDA. [16 March 2006]. Available from: http://www.fda.gov/ohrms/dockets/dockets/06p0123/06p-0123cp00001-01-vol1.pdf

58. Jeal W, Benfield P. Transdermal fentanyl: a review of its pharmacological properties and therapeutic efficacy in pain control. Drugs. 1997;53:109-138.

59. Cephalon, Inc. [webpage on the Internet]. Salt Lake City, UT. Actiq prescribing information [updated Feb 2007; cited 
1 March 2008]. Available from: http://www.actiq.com/pdf/ actiq_package_insert_4_5_07.pdf

60. Stevens RA, Ghazi SM. Routes of opioid analgesic therapy in the management of cancer pain. Cancer Control. 2000;7: $132-141$.

61. Varvel JR, Shafer SL, Hwang SS, et al. Absorption characteristics of transdermally administered fentanyl. Anesthesiology. 1989;70:928-934.

62. Grond S, Radbruch L, Lehman KA. Clinical pharmacokinetics of transdermal opioids: focus on transdermal fentanyl. Clin Pharmacokinet. 2000;38:59-89.

63. Mystakidou K, Katsouda E, Tsilika E, et al. Transdermal therapeutic fentanyl-system (TTS-F). In Vivo. 2004;18:633-642.

64. Freynhagen R, Jürgen von Giesen $H$, Busche $P$, et al. Switching from reservoir to matrix systems for the transdermal delivery of fentanyl: a prospective, multicenter pilot study in outpatients with chronic pain. J Pain Symp Manage. 2005;30: 289-297.

65. Mylan Pharmaceuticals Inc. [webpage on the Internet]. Morgantown, WV. Mylan ${ }^{\circledR}$ Fentanyl Transdermal System, approved prescribing information [updated December 2006; 1 March 2008]. Available from: http://www.mylanpharms.com/ pdfs/07-04-27_fentanyl_v14.pdf

66. Mylan Technologies [webpage on the Internet]. Comments of Mylan Technologies Inc. on Docket No. 2004P0506: To require comprehensive risk minimization programs for fentanyl matrix systems and to treat fentanyl matrix systems as different dosage forms than fentanyl reservoir systems [updated XXXX; cited 1 March 2008]. Available from: http://www.fda.gov/ ohrms/DOCKETS/dockets/04p0506/04p-0506-c000001-01-vol1.pdf

67. Alza Corporation [webpage on the Internet]. Re: Docket No. 2004P-0506 (fentanyl transdermal products), dated January 12, 2005 [updated 12 January 2005; cited 1 March 2008]. Available from: http://www.fda.gov/ohrms/dockets/dockets/04p0506/ 04p-0506-rc00001-01-vol2.pdf

68. Food and Drug Administration, Center for Drug Evaluation and Research [webpage on the Internet]. Approved Drug Products with Therapeutic Equivalence Evaluations. 28th Edition. Washington, DC [updated XXXX; cited 1 March 2008]. Available from: http://www.fda.gov/cder/ob/docs/preface/ ecpreface.htm\#Therapeutic\%20Equivalence-Related\%20Terms

69. Fiset P, Cohane C, Browne S, et al. Biopharmaceutics of a new transdermal fentanyl device. Anesthesiology. 1995;83:459-469.

70. Marier JF, Lor M, Potvin D, et al. Pharmacokinetics, tolerability, and performance of a novel matrix transdermal delivery system of fentanyl relative to the commercially available reservoir formulation in healthy subjects. J Clin Pharmacol. 2006;46:642-653.

71. Ross JR, Quigley C. Transdermal fentanyl: informed prescribing is essential. Eur J Pain. 2003;7:481-483.

72. Holley FO, Van Steennis C. Postoperative analgesia with fentanyl: pharmacokinetics and pharmacodynamics of constant-rate IV and transdermal delivery. $\mathrm{Br} J$ Anaesth. 1988;60:608-613.
73. Portenoy RK, Southam MA, Gupta SK, et al. Transdermal fentanyl for cancer pain: repeated dose pharmacokinetics. Anesthesiology. 1993;78:36-43.

74. Fung DL, Eisele JH. Fentanyl pharmacokinetics in awake volunteers. J Clin Pharmacol. 1980;20:652-658.

75. Hwang SS, Nichols KC, Southam MA. Transdermal permeation: physiological and physicochemical aspects. In: Lehmann KA, Zech D, eds. Transdermal fentanyl. Berlin: Springer 1991:1-7.

76. Roy SD, Hou SYE, Witham SL, et al. Transdermal delivery of narcotic analgesics: comparative metabolism and permeability of human cadaver skin and hairless mouse skin. J Pharm Sci. 1994;83:1723-1728.

77. Thompson JP, Bower S, Liddle AM, et al. Perioperative pharmacokinetics of transdermal fentanyl in elderly and young adult patients. Br J Anaesth. 1998;81:152-154.

78. Zernikow B, Michel E, Anderson B. Transdermal fentanyl in childhood and adolescence: a comprehensive literature review. J Pain. 2007;8:187-207.

79. Cartwright P, Prys-Roberts C, Gill K, et al. Ventilatory depression related to plasma fentanyl concentrations during and after anesthesia in humans. Anesth Analg. 1983;62: 966-974.

80. Shibutani K, Inchiosa MA Jr, Sawada K, et al,. Pharmacokinetic mass of fentanyl for postoperative analgesia in lean and obese patients. Br J Anaesth. 2005;95(3):377-383.

81. Shibutani K, Katoh T, Sakai T, et al. Clinical applications of fentanyl pharmacokinetics and pharmacodynamics: roles of fentanyl in anesthesia. J Anesth. 1999;13(4):209-216.

82. Sabatowski R, Petzke F, Brunsch-Radbruch A, et al. Transdermal fentanyl for the management of cancer pain: a survey of 1005 patients. Palliat Med. 2001;15:309-321.

83. Streisand JB, Bailey PL, LeMaire L, et al. Fentanyl-induced rigidity and unconsciousness in human volunteers: incidence, duration, and plasma concentrations. Anesthesiology. 1993;78: 629-634.

84. Vielvoye-Kerkmeer AP, Mattern C, Uitendaal MP. Transdermal fentanyl in opioid-naive cancer pain patients: an open trial using transdermal fentanyl for the treatment of chronic cancer pain in opioid-naïve patients and a group using codeine. J Pain Symptom Manage. 2000;19:185-192.

85. Tawfik MO. Use of transdermal fentanyl without prior opioid stabilization in patients with cancer pain. Curr Med Res Opin. 2004;20:259-267.

86. Welsh J, Reid A, Graham J, et al. Physicians' knowledge of transdermal fentanyl. Palliat Med. 2005;19:9-16.

87. Booth JV, Grossman D, Moore J, et al. Substance abuse among physicians: A survey of academic anesthesiology programs. Anesth Analg. 2002;95:1024-1030.

88. Kram TC, Cooper DA, Allen AC. Behind the identification of china white. Anal Chem. 1981;53:1379A-1386A.

89. LaBarbera M, Wolfe T. Characteristics, attitudes and implications of fentanyl use based on reports from self-identified fentanyl users. J Psychoactive Drugs. 1983;15:293-301. 
90. Jost U, Wolter E, Bohrer H. Repeated improper intravenous injection of fentanyl from a transdermal system. Dtsch Med Wochenschr. 2004;129:313-314.

91. Reeves MD, Ginifer C. Fatal intravenous misuse of transdermal fentanyl. Med J Aust. 2002;18:552-553.

92. Purucker M, Swann W. Potential for duragesic patch abuse (letter). Ann Emerg Med. 2000;35:314.

93. Tharp AM, Winecker RE, Winston DC. Fatal intravenous fentanyl abuse: four cases involving extraction from transdermal patches. Am J Forensic Med Pathol. 2004;25:178-181.

94. Lilleng PK, Mehlum LI, Bachs L, et al. Deaths after intravenous misuse of transdermal fentanyl. J Forensic Sci. 2004;49:1-3.

95. Sellers EM, Schuller R, Romach MK, et al. Relative abuse potential of opioid formulations in Canada: a structured field study. J Opioid Manag. 2006;2:219-227.

96. Marquardt KA, Tharratt RS. Inhalational abuse of fentanyl patch. Clin Toxicol. 1994;32:75-78.

97. Barrueto F, Howland MA, Hoffman RS, et al. The fentanyl tea bag. Vet Human Toxicol. 2004;46:30-31.

98. Coon TP, Miller M, Kaylor D, et al. Rectal insertion of fentanyl patches: a new route of toxicity (letter). Ann Emerg Med. 2005;46:473.

99. van Rijswijk R, van Guldener C. A delirious patient with opioid intoxication after chewing a fentanyl patch. J Am Geriatr Soc. 2006;54:1298-1299.

100. Teske J, Weller JP, Larsch K, et al. Fatal outcome in a child after ingestion of a transdermal fentanyl patch. Int J Legal Med. 2007;121:147-151.

101. Cephalan, Inc. [webpage on the Internet]. Important Safety Information for Fentora (Dear Doctor letter). Frazer, PA [updated 10 September 2007; 1 March 2008]. Available from: http://www.fentora.com/pdf/fentora_ddl.pdf.

102. Marquardt KA, Tharratt RS, Musallam NA. Fentanyl remaining in a transdermal system following three days of continuous use. Ann Pharmacother. 1995;29:969-971.

103. Flannagan LM, Butts JD, Anderson WH. Fentanyl patches left on dead bodies: potential source of drug abusers. J Forensic Sci. 1996;41:320-321.

104. Gardner-Nix J. Caregiver toxicity from transdermal fentanyl. J Pain Symptom Manage. 2001;21:447-448.
105. Hardwick WE, King WD. Respiratory depression in a child unintentionally exposed to transdermal fentanyl patch. South Med J. 1997;90:962-965.

106. Janssen Pharmaceuticals [webpage on the Internet]. Urgent product recall. $75 \mathrm{mcg} / \mathrm{hr}$ Duragesic patches. Titusville, NJ [updated 17 February 2004; cited 1 March 2008]. Available from: http://www.fda.gov/medwatch/SAFETY/2004/duragesic_ recall.pdf

107. Janssen Pharmaceuticals [webpage on the Internet]. Urgent expanded product recall. $75 \mathrm{mcg} / \mathrm{hr}$ Duragesic patches. Titusville, NJ [updated 7 April 2004; cited 1 March 2008]. Available from: http://www.fda.gov/cder/drug/shortages/duragesicLetter.pdf

108. US Food and Drug Administration [webpage on the Internet]. Actavis Recalls Certain Fentanyl Patches in the US as Precaution. Washington, DC [updated 19 February 2008; 1 March 2008]. Available from: http://www.fda.gov/oc/po/ firmrecalls/actavis02_08.html

109. US Food and Drug Administration [webpage on the Internet]. Pricara recalls $25 \mathrm{mcg} / \mathrm{hr}$ Duragesic (fentanyl transdermal system) CII pain patches. Washington, DC [updated 12 February 2008; 1 March 2008]. Available from: http://www.fda.gov/oc/ po/firmrecalls/pricara02_08.html.

110. Henderson GL. Fentanyl-related deaths: demographics, circumstances, and toxicology of 112 cases. J Forensic Sci. 1991;36(2):422-433.

111. Rainey PM. Laboratry Principles. In: Flomenbaum NE, Goldfrank LR, Hoffman RS, Howland MA, Lewin N, Nelson LS, eds. Goldfrank's Toxicologic Emergencies. 8th ed. McGraw-Hill: New York; 2006:88-108.

112. Thomasy SM, Mama KR, Stanley SD. Comparison of liquid chromatography-mass spectrometry and radioimmunoassay for measurement of fentanyl and determination of pharmacokinetics in equine plasma. J Anal Toxicol. 2008;39:754-759.

113. Thompson JG, Baker AM, Bracey AH, et al. Fentanyl concentrations in 23 postmortem cases from the Hennepin County medical eexaminer's office. J Forensic Sci. 2007;52: 978-981.

114. Pizon AF, Brooks DE. Fentanyl patch abuse: naloxone complications and extracorporeal membrane oxygenation rescue. Vet Human Toxicol. 2004;46:256-257. 